\title{
Rare Associations Of Primary Biliary Cirrhosis: A Review Article
}

\author{
T Rodriguez, E Latour, P Patel, M Niazi, A Bloom, B Balar, S Carvajal
}

\section{Citation}

T Rodriguez, E Latour, P Patel, M Niazi, A Bloom, B Balar, S Carvajal. Rare Associations Of Primary Biliary Cirrhosis: A Review Article. The Internet Journal of Gastroenterology. 2007 Volume 7 Number 1.

DOI: $\underline{10.5580 / 1197}$

\begin{abstract}
Primary Biliary Cirrhosis (PBC) is the most common chronic cholestatic liver disease in adults in the United States (16). There are several rare conditions associated with PBC. We review all reported associations and present our own case experience. The list of these conditions is extensive but the numbers of cases are limited. Our aim is to make the physicians aware of these rare associations and help in the diagnosis.

A few cases of multiple myeloma in early stages of PBC have been described (3). We report a patient who presented with severe coagulopathy in whom antimitochondrial antibodies were positive. Despite normal liver transaminases and alkaline phosphatase as in previously reported cases (13), liver biopsy showed advanced cirrhosis and histological changes consistent with PBC. A concurrent diagnosis of multiple myeloma IGG type was made by bone marrow biopsy. A possible pathophysiologic mechanism is described.
\end{abstract}

\section{INTRODUCTION}

The etiology of Primary Biliary Cirrhosis remains unclear. Several lines of evidence support an autoimmune pathogenesis: the presence of activated $T$ cells in areas of bile duct destruction, the occurrence of highly specific autoantibodies that react with antigens localized on biliary epithelial cells, and the association of PBC with other disorders thought to be autoimmune in nature $\left(_{15}\right)$. Genetic and environmental factors have been implicated $\left({ }_{15}\right)$. Primary biliary cirrhosis (PBC) represents the most common chronic cholestatic liver disease in adults in the United States $\left({ }_{15}\right)$. It has been described in association with other entities. We report a case of PBC and multiple myeloma and conduct a review of available literature on rare conditions associated with PBC.

\section{PRIMARY BILIARY CIRRHOSIS ASSOCIATED WITH MULTIPLE MYELOMA \\ CASE HISTORY}

A 68-year-old woman was admitted to the Bronx Lebanon Hospital with complaints of dizziness, near syncope and lower back pain. There was no history of fatigue, tiredness, pruritus or any toxic habits. She had a history of hypertension and bronchial asthma.
On admission physical examination revealed multiple ecchymotic skin lesions most prominent on the abdominal wall and thighs. Multiple subcutaneous nodules were noted in the abdominal wall as well. The liver was not palpable and neither shifting dullness nor peripheral edema was found.

\section{LABORATORY DATA}

Laboratory findings on admission included AST: $24 \mathrm{u} / 1$ (NV: 9-48 u/l), ALT: $17 \mathrm{u} / \mathrm{l}(\mathrm{NV}: 5-40 \mathrm{u} / \mathrm{l})$, alkaline phosphatase: $129 \mathrm{u} / \mathrm{l}(\mathrm{NV}: 53-128 \mathrm{u} / \mathrm{l})$, total bilirubin:1.0 (NV: 0.2-1.2 mg/dl), direct bilirubin: 0.4 (NV: 0.0-0.3 $\mathrm{mg} / \mathrm{dl}$ ), platelet count: $208 \mathrm{k} / \mu \mathrm{l}(\mathrm{NV}: 150-350 \mathrm{k} / \mu \mathrm{l})$, and albumin: $2.9 \mathrm{~g} / \mathrm{dl}$ (NV:3.4-4.8 g/dl). Antinuclear antibodies were negative as were tests for hepatitis B and $\mathrm{C}$ viruses. Rheumatoid Factor was normal. Serum protein electrophoresis (SPEP) showed a spike in the gamma region with a total protein of 8.6 and gammaglobulins of $39.6 \%$.

Urine protein electrophoresis showed no monoclonal protein.

Quantification of the immunoglobulins in the serum revealed the following values: IGG-4750 mg/dl (N: 844-1912 mg/dl), IGM 100mg/dl ( N: 50-196 mg/dl), IGA 191mg/dl (N: 68-423 mg/dl). Alpha-feto-protein and carcino-embryonic 
antigen were normal.

The coagulation profile revealed a decrease in factors $\mathrm{V}$, VII, IX consistent with liver disease as shown in table 1.

\section{Figure 1}

Table 1: Summary of coagulation factors in this patient.

\begin{tabular}{|l|c|}
\hline Factor V & $5($ N: $50-150 \%)$ \\
\hline Factor VII & $22(\mathrm{~N}: 50-150 \%)$ \\
\hline Factor DX & $75(\mathrm{~N}: 50-150 \%)$ \\
\hline Factor X & $45(\mathrm{~N}: 50-150 \%)$ \\
\hline
\end{tabular}

A computed tomography of the abdomen revealed a dense nodular liver suggestive of cirrhosis. There was no ascites. Multiple heterogeneous masses were seen in the RUQ, peripancreatic region and in subcutaneous tissues of the anterior abdominal wall.

Biopsies of the abdominal wall nodules and a right axillary lymph node showed fat necrosis and reactive lymphadenopathy, respectively. Bone marrow biopsy showed plasmocytosis of $28 \%$ consistent with the diagnosis of multiple myeloma. (Fig. 1-a).

\section{Figure 2}

Figure 1a: Bone marrow aspirate with sheets of plasma cells

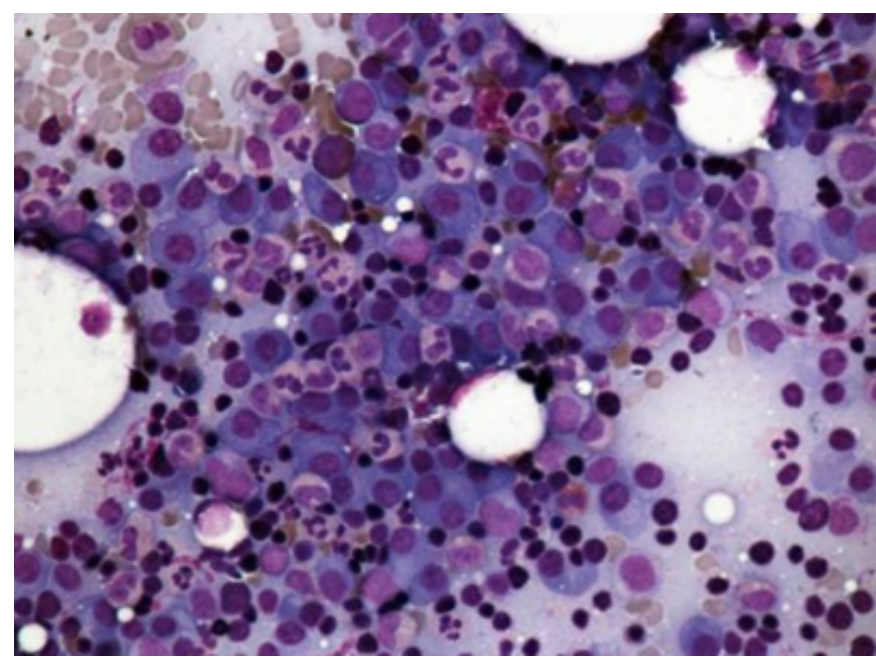

The patient was started on 40 milligrams of dexamethasone for treatment of multiple myeloma. The patient's clinical condition and coagulopathy improved. Table 2 summarizes the effects of prednisone treatment on laboratory in this patient.
Figure 3

Table 2: Effect of prednisone therapy on laboratory values

\begin{tabular}{|l|c|l|}
\hline & Pre-trealment & Post-treament \\
\hline $\mathrm{Hb} / \mathrm{Hct}$ & $9.3 / 28^{*}$ & $10.8 / 31.4$ \\
\hline AMA & $3+$ - & Negative \\
\hline Prothrombin time/ INR & $24.1 / 2.5^{*}$ & $11.7 / 1.1$ \\
\hline B2 microglobulin & $4.48 \mathrm{mg} / \mathrm{dl} *$ & $2.66 \mathrm{mg} / \mathrm{dl}$ \\
\hline $\begin{array}{c}\text { Gammaglutamyltranspeptidase } \\
\text { (Normal 8-54 I/U) }\end{array}$ & $205 \mathrm{I} / \mathrm{U}^{*}$ & $138 \mathrm{I} / \mathrm{U}$ \\
\hline *Abnormal value. & & \\
\hline
\end{tabular}

A CT guided liver biopsy showed complete loss of acinar architecture with nodule formation. The portal tracts showed ductopenia, ductular proliferation, chronic inflammatory cell infiltrate and Mallory bodies. No granulomas were seen. The histological features were consistent with PBC (Fig. 1-b). Masson trichrome stain showed increased portal fibrosis with established cirrhosis (Fig. 1-c).

\section{Figure 4}

Figure 1b: Liver cirrhosis: A widened portal tract with ductopenia and chronic inflammatory cell infiltrate (Hematoxylin and eosin)

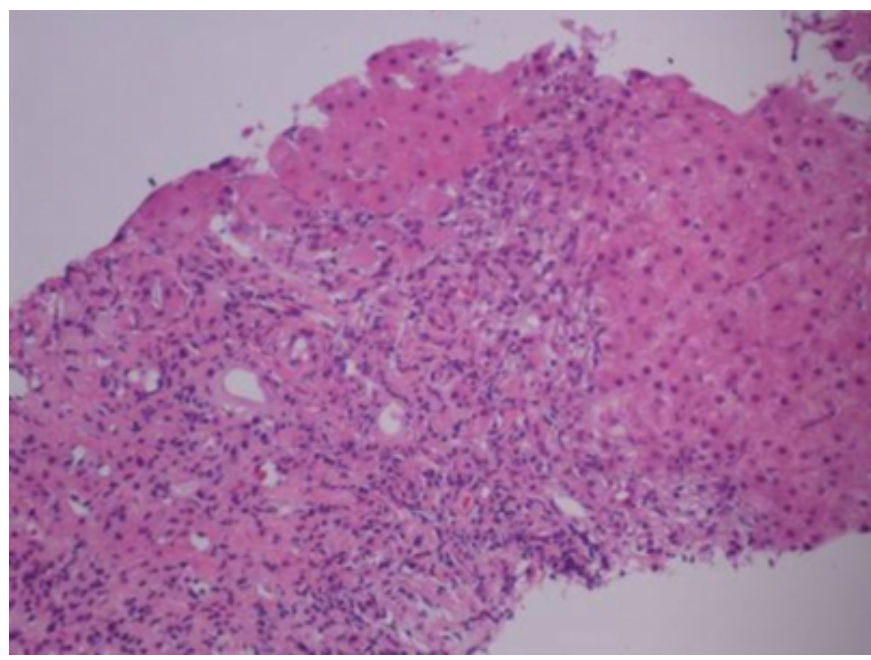




\section{Figure 5}

Figure 1c: Liver cirrhosis: Portal fibrosis with hepatocellular regenerative nodules (Masson Trichrome stain)

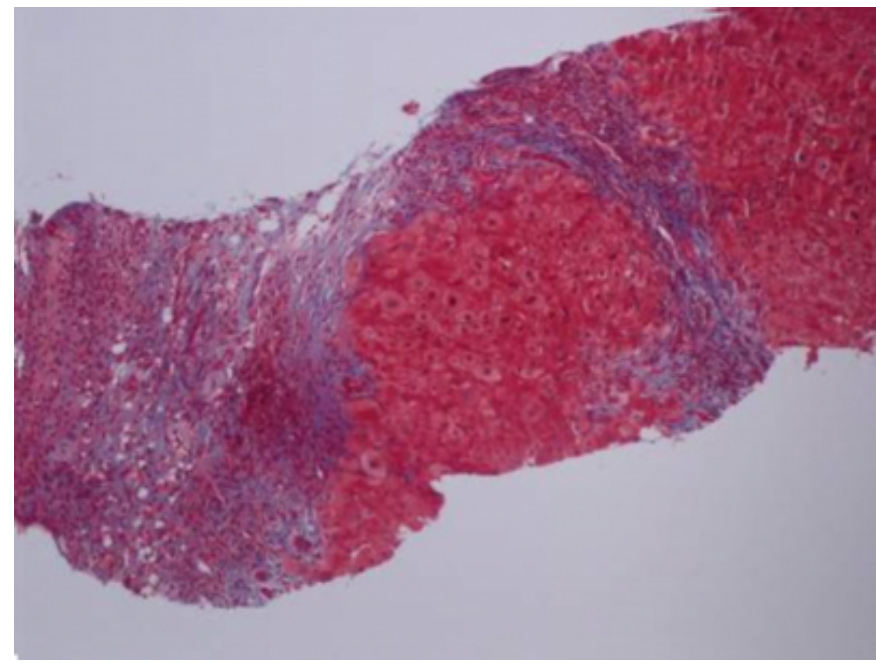

Biopsy of the peripancreatic lymph nodes was unsuccessful, revealing only fibrin, blood and minute fragments of fibrous tissue, but no pancreatic or lymphoid tissue obtained.

The patient was discharged home on a tapering dose of dexamethasone. She was readmitted one week after discharge due to bleeding from the lymph node biopsy site in the abdomen. She was observed, but no specific treatment was given. Hospital stay was unremarkable. Upon discharge her INR was 1.7.

Currently she is stable and is followed at the Oncology clinic.

Pathogeneses and Diagnosis: Antimitochondrial antibodies are the serologic hallmark of PBC. Most AMA react against the dihydrolipoamide acetyltransferase component (E2 subunit) of pyruvate dehydrogenase complex (PDC-E2) $\left({ }_{7}, 8,9,10,16\right)$. PDC-E2-reacting antibodies are present in $90 \%$ to $95 \%$ of PBC sera $\left({ }_{16}\right)$.

There are other AMA antibodies present, like the ones directed against the $\mathrm{E} 2$ unit of the branched-chain 2-oxo-acid dehydrogenase complex (BCOADC-E2), the E2 subunit of the 2-oxo-glutarate dehydrogenase complex (OGDC-E2), the E1 1 subunit of PDC and the dihydrolipoamide dehydrogenase- binding protein (E3BP), but these are much less frequent $\left({ }_{16}\right)$

T lymphocytes, CD4+ and CD8+, are present in high concentration in the portal triads of patients with $\mathrm{PBC}$, often surrounding and infiltrating necrotic bile ducts. Autoreactive $\mathrm{T}$ lymphocytes from $\mathrm{PBC}$ patients are specific for
PDC-E2. PDC-E2, normally found in the inner mitochondrial membrane of all cells, is aberrantly expressed in the luminal surface of bile duct epithelial cells only in patients with $\operatorname{PBC}\left({ }_{5}\right)$.

$\mathrm{PBC}$ is the only disease in which there are B- and T-cells that are auto-reactive against PDC-E2.

The serum aminotransferases may be normal or slightly elevated, but rarely are increased more than fivefold above normal. Serum alkaline phosphatase is almost always elevated, however there are case reports of patients presenting with normal values $\left(_{13}\right)$.

The serum bilirubin concentration may be normal but increases in almost every patient with disease progression.

The number of eosinophils may be increased in the blood and liver of PBC patients, which suggests a possible pathogenic role in this disease. Other significant laboratory abnormalities seen in PBC patients are increase cholesterol levels and positive antinuclear antibodies in up to fifty and seventy percent of PBC patients respectively.

\section{DISCUSSION}

There are several entities that have commonly associated with PBC (table 3) and other less common diseases have also been reported, MM is among them. Extrahepatic malignancies typically B cell lymphomas have been described in patients with primary biliary cirrhosis (PBC) $\left(_{1}\right)$. Polyclonal hypergammaglobulinemia is common in chronic liver disease $\left({ }_{1}, 2\right)$, but only in rare instances has monoclonal gammopathy been found $\left({ }_{1}, 2\right)$.

\section{Figure 6}

Table 3: Commonly accepted associations with primary biliary cirrhosis

\begin{tabular}{|l|c|}
\hline Disease & Frequency (\%) \\
\hline Keratoconjunctivitis sicca (Sjögren's syndrome) & $72-100$ \\
\hline Autonomic dysfunction (23) & $81-100$ \\
\hline Renal tubular acidosis & $50-60$ \\
\hline Gallstones & 33 \\
\hline Scleroderma and its variants (16,55) & $15-19$ \\
\hline Autoimmune thyroiditis & $15-20$ \\
\hline Arthritis/arthropathy & $4-42$ \\
\hline
\end{tabular}

Hyper-gammaglobulinemnia in PBC is thought to be related to polyclonal $\mathrm{B}$ cell activators, defects of hepatic clearance of antigens from the gut, or immunologic imbalance between lymphocyte suppressor and helper functions $\left({ }_{1}, 2\right)$.

A decreased in supressor T-cell function in patients with 
PBC has been demonstrated $\left(_{3}\right)$. B cell hyperactivity with enhanced production of immunoglobulins or autoantibodies appears to be related to this T-cell dysfunction $\left(_{3}\right)$.

Monoclonal gammopathy occurring in the course of chronic liver disease is rare and in most cases benign $\left({ }_{2}\right)$. Only a few cases of PBC associated with multiple myeloma and other lymphoproliferative disorders have been reported $\left({ }_{1,2}, 3,3_{4},{ }_{14}\right)$. The precise mechanisms of association of PBC and multiple myeloma are not clear, but alterations of both cellular and humoral immune functions have been suggested to play a major role in its pathogenesis $\left({ }_{1}, 4\right)$. Transformation of polyclonal to monoclonal gammopathy has also been reported.

There are conflicting data as to whether serum GGT has better sensitivity for hepatobiliary disease than alkaline phosphatase or leucine aminopeptidase $\left({ }_{11},{ }_{12}\right)$.

The liver biopsy in our case was consistent with advanced cirrhosis, this differs from the early stages of the disease reported in the four cases that had biopsies done previously $(2,3,4)$. The myeloma, as in six out of the eleven previously reported cases had a monoclonal protein of IgG type $\left({ }_{1,2}, 3,4,4\right)$. Our case had a lambda light chain. Of interest our patient had marked eosinophilia 10\% (NV: <6) and 1.34 absolute count (NV: 0.05-0.25K/uL).

The reason for the dramatic improvement of the coagulopathy with steroid treatment remains unclear. There are two reports of improvement of serum markers of PBC, specifically alkaline phosphatase and serum Ig M levels after chemotherapy of myeloma $\left({ }_{1}\right)$, another case reports improvement also on coagulation profile of PBC patient after myeloma treatment $\left({ }_{13}\right)$ with melphalan and prednisone. Our case is unique in the dramatic response of coagulopathy and seroconversion of AMA to treatment with prednisone only. It also differs from the majority of previously reported cases of this rare association in the presence of normal alkaline phosphatase, despite an elevated gammaglutamyl transpeptidase. Table 3 summarizes the commonly accepted associations of $\mathrm{PBC}$ and table 4 the rare associations found in our review.

\section{Figure 7}

Table 4: summarizes the rare associations and the number of cases found in the literature.

\begin{tabular}{|c|c|c|}
\hline Condition & Cases reported & Ref. No. \\
\hline Acute leukemia & 2 & 16 \\
\hline Microscopic polyangutis & 2 & 17,21 \\
\hline Hegatic inflammatory pseudotumor & 2 & 18,57 \\
\hline SPIDDM & 1 & 19 \\
\hline Takayasu's arteritis & 1 & 20 \\
\hline Evans syndrome & 1 & 22 \\
\hline Pure whate cell aplasxa & 1 & 24 \\
\hline Syringomyetsa & 2 & 26 \\
\hline Bronchitis Obliterans & 1 & 27 \\
\hline Autoimmune hemolysis & 1 & 28 \\
\hline Bullous pemphigoid & 4 & 29 \\
\hline Anterior Uvetis & 1 & 30 \\
\hline Itiopathic myelofibrosis & 1 & 14 \\
\hline Idiopathic retroperitoneal fibrosis & 2 & 31,32 \\
\hline Penicious anemia & 5 & $33,34,35$ \\
\hline Overlap collagen vascular disease & 1 & 36 \\
\hline $\begin{array}{l}\text { Turner syndrome, aquired von Willebrand } \\
\text { disease, IBD and PBC }\end{array}$ & 1 & 37 \\
\hline Cutaneous T cell lymphoma & 1 & 38 \\
\hline Minimal change glomerulonephrits & 1 & 39 \\
\hline Uicerative colitis & 19 & $25,40,56$ \\
\hline Reynaud's syndrome & 1 & 41 \\
\hline Non-Hodgkin's lymphoma & 1 & 42 \\
\hline Polymyositis & 22 & 43 \\
\hline Cutaneous polyartentis nodosa & 1 & 44 \\
\hline $\begin{array}{l}\text { Hepatic marginal zone B-cell lymphoma, } \\
\text { Primary hepatic lymphoma }\end{array}$ & 3 & $45,46,47$ \\
\hline Lichen Planus & 25 & 48 \\
\hline Myasthenia gravis & 2 & 49,56 \\
\hline Type Il autoimmune polyglandular syndrome & 1 & 50 \\
\hline Chronic thyroiditis & 2 & 51,52 \\
\hline Autoimmune hypophysitis & 1 & 53 \\
\hline SLE & 1 & 54 \\
\hline Multiple myeloma & 11 & $1,2,58,3,4,59,12,13$ \\
\hline Cutaneous amyloidosis & 1 & 60 \\
\hline
\end{tabular}

\section{CONCLUSION}

Polyclonal gammopathy is common in the course of chronic liver disease but one should be aware of the possibility of an associated monoclonal gammopathy.

Monoclonal gammopathy is rare in chronic liver disease and if present we suggest that malignancy be ruled out and multiple myeloma be considered in the differential diagnosis. Alkaline phosphatase may be normal in the course 
of advanced primary biliary cirrhosis, as in this case, and obtaining gammaglutamyltranspeptidase may be of value. Certain laboratory parameters may be expected to improve specifically coagulation profile, transaminases and AMA titer after treatment for multiple myeloma in the setting of its association with primary biliary cirrhosis.

Glossary terms: PBC (Primary biliary cirrhosis), ANA (antinuclear antibodies), AMA (antimitochondrial antibodies), SPIDDM (slowly progressive insulin dependent diabetes mellitus)

\section{References}

1. Haruo Kaneko, Takao Endo et al. Primary Biliary Cirrhosis associated with Multiple Myeloma. Internal Medicine 32:802-805, 1993.

2. Fujii H, Yashige H. Kintsho Ketsucki. 1989 Oct;30 (10): 1886-91 Multiple myeloma of IgG-lambda type associated with asymptomatic primary biliary cirrhosis. (Abstract only) 3. Joan Blade, Emili Montserrat, Miguel Bruguera et al. Multiple myeloma in Primary Biliary Cirrhosis. Scand J Hematology (1981) 26, 14-18.

4. Hitoshi Amakasu, Atsushi Kanno and Masahide Abe. Multiple myeloma occurring in early stage Primary Biliary Cirrhosis. Tohoku J Exp. Med.1993, 169, 197-203.

5. Migliaccio, C, Van de Water, J, Ansari, AA, et al. Heterogeneus response of antibodies and bile duct apical staining monoclonal antibodies to pyruvate dehydrogenase complex E2: The molecule versus the mimic. Hepatology 2001; 33: 792.

6. Van de Water, J, Cooper, A, Surh, CD, et al. Detection of the autoantibodies to recombinant mitochondrial proteins in patients with primary biliary cirrhosis. N Engl J Med 1989; 320: 1377.

7. Van de Water, J, Fregeau, D, Davis, P, et al.

Autoantibodies of primary biliary cirrhosis recognize dihydrolpoamide acetyltransferase and inhibit enzyme function. J Immunol 1988; 141:2321.

8. Nishio, A, Coppel, R, Ishibashi, H, Gershwin, ME. The pyruvate dehydrogenase complex as a target autoantigen in primary biliary cirrhosis. Baillieres Best Pract Res Clin Gastroenterol 2000; 14:535

9. Shigematsu, H, Shimoda, S, Nakamura, M, et al. Fine specificity of T cells reactive to human PDC-E2 163-176 peptide, the immunodominant autoantigen in primary biliary cirrhosis: implications for molecular mimicry and crossrecognition among mitochondrial autoantigens. Hepatology 2000; 32:901

10. Lum, G, Gambino, SR. Serum gamma-glutamyl transpeptidase activity as an indicator of disease of liver, pancreas, or bone. Clin Chem 1972; 18:358

11. Betro, MG, Oon, RC, Edwards, JB. Gamma-glutamyl transpeptidase in diseases of the liver and bone. Am J Clin Pathol 1973; 60:672

12. Lazarro Antonio, Bernuzzi P, Arcari A, Berte R, Moroni F C, Trabacchi E, Valissa D, Cavanna L. A singular case of Multiple Myeloma and Primary Biliary Cirrhosis Strictly associated in Pathogenesis and Response to Alkylating Therapy Wiley Inter Science DO: 10.1002/AJH.20586 13. Kalliopi Zachou, Eirini Rigopoulou, Christos Liaskos et al. Primary Biliary Cirrhosis presented as peripheral eosinophillia in asymptomatic women with or without elevated alkaline phosphatase. European Journal of Gastroenterology and Hepatology 2004, 16:425-428
14. Hernandez-Boluda JC, Jimenez M, Rosiño L, Cervantes F. Idiopathic myelofibrosis associated with primary biliary cirrhosis. Leuk Lymphoma. 2002 Mar;42(3):673-4

15. Feldman: Sleisenger \& Fordtran's Gastrointestinal and Liver Disease, 8th ed. p 1885-96

16. Saito H, Monoe K, Kanno Y, Takahashi A, Rai T, Irisawa A, Ohira $\mathrm{H}$. Two cases of primary Biliary cirrhosis complicated by acute leukemia. Intern Med.

2007;46(9):561-3 Epub 2007 May 1

17. Iannone F, Falappone P, Pannarale G, Gentile A, Grattagliano V, Covelli M, Lapadula G. Microscopic polyangitis associated with primary Biliary cirrhosis. J Rheumatol. 2003 Dec;30(12):2710-2

18. Koide H, Sato K, Fukusato T, Kashiwabara K, Sunaga N, Tsuchiya T, Morino S, Sohara N, Kakizaki S, Takagi H, Mori M. Spontaneous regression of hepatic inflammatory pseudotumor with primary biliary cirrhosis: case report and literature review. World J Gastroenterol. 2006 Mar

$14 ; 12(10): 1645-8$

19. Nakasone H, Kinjo K, Yamashiro M, Kamiyama T, Kamiyama S, Miyazato H, Matsushita T, Arakawa Y, Ohshiro T, Toma S, Chinen K, Yamashiro M, Miyagi M, Makishi T, Hokama A, Sakugawa H, Kinjo F, Saito A. A patient with primary Biliary cirrhosis complicated with slowly progressive insulin-dependent diabetes mellitus. Intern Med. 2003 Jun;42(6):496-9

20. Ito S, Ohkoshi S, Aoyagi T, Suzuki K, Takahashi T, Nomoto M, Nakano M, Arakawa M, Asakura H, Gejyo F. A patient with Takayasu's arteritis treated with corticosteroids who develop primary Biliary cirrhosis. Intern Med. 2003 May;42(5):443-5

21. Amezcua-Guerra LM, Prieto P, Bojalil R, Pineda C, Amigo MC. Microscopic polyangiitis associated with primary biliary cirrhosis: a causal or casual association? J Rheumathol. 2006 Nov;33(11):2351-3. Epub 2006 Sep 15 22. Azad A, Berera V, Jayarajan J, Lim K. Evans syndrome and primary biliary cirrhosis. Int J Lab Hematol. 2007 Apr;29(2):145-8

23. Caramella Newton JL, Davidson A, Kerr S, Bhala N, Pairman J, Burt J, Jones DE. Autonomic dysfunction in primary biliary cirrhosis correlates with fatigue severity. Eur J Gastroenterol Hepatol. 2007 Feb;19(2):125-32

24. Pure white cell aplasia: report of the first case asssocairted with primart biliary cirrhosis. Tamura $\mathrm{H}$,

Okamoto M, Yamashita T, Sato C et al. Int J Hematol. 2007 Feb;85(2):97-100

25. Xiao WB, Liu YL. Primary biliary cirrhosis and ulcerative colitis: a case report and review of literature. World J Gastroenterol. 2003 Apr;9(4):878-80

26. Ohira H, Takiguchi J, Shishido S, Sato Y. Two cases of primary Biliary cirrhosis complicated with syringomyelia.

Am J Gastroenterol. 2003 Jan;98(1):224-6

27. Montero C, Brage A, Rodriguez-Trigo G, Verea H.

Bronchiolitis obliterans with organizing pneumonia and primary Biliary cirrhosis. Med Clin (Barc). 2003 Jan $18 ; 120(1): 37-8$

28. Fuller SJ, Kumar P, Weltman M, Wiley JS. Autoimmune hemolysis associated with primary biliary cirrhosis responding to ursodeoxycholic acid as sole treatment. Am J Hematol. 2003 jan;72(1):31-3

29. Marcet B, Sibaud V, Geniaux M, Taieb A. Bullous pemphigoid, primary biliary cirrhosis and vitiligo: a multiple autoimmune syndrome. Ann Med interne (Paris). 2002 sep; $153(5): 349-50$

30. Tekeli O, Ozdemir O. Anterior uveitis and sjogren's syndrome in a patient with primary biliary cirrhosis. Can J Ophthalmol. 2002 Oct; 37(6):359-60

31. Tang KH, Schofield JB, Powell-Jackson PR. Primary 
biliary cirrhosis and idiopathic retroperitoneal fibrosis rare association. Eur J Gastroenterol hapatol. 2002

Jul;14(7):783-6

32. Shikuwa S, Omagari K, Mizuta Y, Murase K, Osabe m, Yoshimura M, Ohfukuji m, Takehara Y, Isomoto H, Ito M, Shimokawa I, Kohno S. Primary biliary cirrhosis associated with idiopathic retroperitoneal fibrosis. Gastroenrol. 2000 ;35(8):646-8

33. Aoyama H, Sakugawa H, Nakasone H, Nakayoshi T, Kinjo A, Tamayose M, Higa H, Uema E, Chinen T,

Tomiyama R, Uchima N, Kugai Y, Saito A, Kinjo M. A rare association of primary biliary cirrhosis and pernicious anemia. J Gastroenterol. 2002 ;37(7):560-3

34. Takahashi T, Honma T, Ishizuka K, Fuse I, Asakura H. A female with asymptomatic primary biliary cirrhosis associated with pernicious anemia. J Gastroenterol Hepatol. 2001 Dec;16(12):1420-4

35. Dohmen K, Nagai Y, Matsuishi E, Miyamoto Y,

Sasatomi E, Irie K, IshibashiH. A case of primary biliary cirrhosis associated with pernicious anemia. Nippon Shokakibyo Gakkai Zasshi. 1999 May ;96(5):545-9

36. Smith KJ, Skelton H. Overlap collagen vascular disease as a marker for development of primary biliary cirrhosis. Int J Dermatol. 2002 Jul;41(7):390-4

37. Sakol L, Stueben Et, Jaikishen JP, Lamarche MB. Turner syndrome associated with acquired von willebrand disease, primary biliary cirrhosis and inflammatory bowel disease.

Am J hematol. 2002 Jul;70(3):257-9

38. Stroehmann A, Dorner T, Lukowsky A, Feist E, Heipe F, Burmester GR. Cutaneous T cell lymphoma in a patient with primary biliary cirrhosis and secondary sjogren's syndrome. J rheumatol. 2002 Jun; 29(6):1326-9

39. Gonzalez Portal C, Quinones L. Primary biliary cirrhosis and minimal change glomerulonephritis. Nefrologia.

2001;21(6):609-10

40. Nakayama M, Tsuji H, Shimono J, Azuma K, Ogata H, Matsumoto T, Aoyagi K, Fujishima M, Iida M. Primary biliary cirrhosis associated with ulcerative colitis. Fukuoka Igaku Zasshi. 2001 Oct;92(10):354-9

41. Brzezinska-Kolarz B, Undas A, Dyczek, Musial J.

Reynolds Syndrome: the combination of scleroderma and primary biliary cirrhosis. Pol Arch Med Wewn. 2001 Mar;105(3):231-4

42. Hahn JS, Kim C, Min YH, Ko YW, Suh CO, Park YY.

Non-Hodgkin's Lymphoma and primary biliary cirrhosis with Sjogren's syndrome. Yonsei Med J. 2001

Apr;42(2):258-63

43. Matsui K, Aizawa Y, Inoue K, Yaguchi H, Toda G.

Polymyositis with marked paravertebral muscle atrophy in patients with primary biliary cirrhosis. Rinsho Shhinkeigaku. 2000 Jul;40(7):694-700

44. Dohmen K, Miyamoto Y, Irie K, Takeshita T, Ishibashi $\mathrm{H}$. Manifestation of cutaneous polyarteritis nodosa during interferon therapy for chronic hepatitis $\mathrm{C}$ associated with primary biliary cirrhosis. J Gastroenterol.

2000;35(10):789-93

45. Ye MQ, Suriawinata A, Black C, Min AD, Strauchen J, Thung SN. Primary hepatic marginal zone B-cell lymphoma of mucosa associated lymphoid tissue type in a patient with primary biliary cirrhosis. Arch Pathol Lab Mad. 2000 Apr;124(4):604-8

46. Lizarralde E, Martinez P, Ibanez T, Gutierrez A. Primary hepatic lymphoma and primary biliary cirrhosis. Am J Gastroenrol. 2000 Feb;95(2):1669-73

47. Sato S, Masuda T, oikawa H, Satoh T, Suzuki Y, Takikawa Y, Yamazaki K, Suzuki K, Sato S. Primary hepatic lymphoma associated with primary biliary cirrhosis. Am J Gastroenrol. 1999 Jun;94(6):1669-73

48. Chu CY, Yang CY, Huang SF, Lu SC, Wang LF. Lichen planus with xanthomatous change in a patient with primary biliary cirrhosis. Br J Dermatol. 2000 Feb;142(2):377-8 49. Horigome H, Nomura T, Saso K, Joh T, Ohara H, Akita S, Sobue S, Mizuno Y, Kato Y, Itoh M. Coexistence of primary biliary cirrhosis and myasthenia gravis: case study. Hepatogastroenterology. 2000Jan-Feb;47(31):125-7 50. Borgaonkar MR, Morgan DG. Primary Biliary cirrhosis and type II autoimmune polyglandular syndrome. Can J Gastroenterol. 1999 Nov;13(9):767-70

51. Wakabayashi T, Ohno H, Hayakawa Y, Kawashima A, Sawabu N. Primary biliary cirrhosis associated with Type A gastritis and chronic thyroiditis. J gastroenterol. 1999 jun;34(3):415-9

52. Sato n, Ohira H, Orikasa H, Shinzawa J, Suzuki T, Tojo J, Miyata M, Nishimaki T, Kasukawa R. Primary biliary cirrhosis associated with painless thyroiditis. Intern Med. 1999 Mar;38(3):244-8

53. Nishiki M, Murakami Y, Koshimura K, Sohmiya M, Tanaka J, Yabe S, Kobayashi I, Kato Y. A case of autoimmune hypophysitis associated with asymptomatic primary biliary cirrhosis. Endocr J. 1998 oct;45(5):697-700 54. Islam S, Riordan JW, McDonald JA. Case report; a rare associateion of primary biliary cirrhosis and systemic lupus erythematosus and review of the literature. J Gastroenterol hapatol. 1999 May;14(5):431-5

55. Takeda I, Igarashi S, Oyanagi H, Irisawa A, Mukai S, Shoji I, Sakuma H, Satho H, Sekine K, Kuroda M. Two cases of asymptomatic primary biliary cirrhosis accompanied with CREST syndrome. Ryumachi. 1994 Aug;34(4):767-72

56. Ito M, McCann P, Pramanik A. Dysphagia and unexpected myasthenia gravis associated with primary biliary cirrhosis, ulcerative colitis and vitiligo. J Am Geriatr Soc. 2004 Aug;52(8):1407-8.

57. Rai T, Ohira H, Tojo J, Takiguchi J, Shishido S, Sato Y, Nozawa Y, Masuda T. A case of hepatic inflammatory pseudotumor with primary biliary cirrhosis. Hepatol Res. 2003 Jul;26(3):249-253

58. Kaneko H, Endo T, Saitoh H, Katsuta Y, Aramaki T, Hayakawa H. Primary biliary cirrhosis associated with multiple myeloma. Intern Med. 1993 Oct;32(10):802-5 59. Rodriguez-Leal GA, Moran-Villota S, Arista-Nasr J, Uribe-Esquivel M. Case report of multiple myeloma and hypothyroidism in primary biliary cirrhosis. Rev Invest Clin. 1997 May-Jun;49(3):215-20

60. Tafarel JR, Lemos LB, Oliveira PM, Lanzoni VP, Ferraz ML. Cutaneous amyloidosis associated with primary biliary cirrhosis. Eur J Gastroenterol Hepatol. 2007 Jul; 19(7):603-5 


\section{Author Information}

Tomas Rodriguez, MD

Fellow in Gastroenterology, Albert Einstein College of Medicine, Bronx-Lebanon Hospital Center

\section{Euyen Latour, MD}

Internal Medicine Resident, Albert Einstein College of Medicine, Bronx-Lebanon Hospital Center

\section{Pikeshkumar Patel, MD}

Fellow in Gastroenterology, Albert Einstein College of Medicine, Bronx-Lebanon Hospital Center

\section{Masooma Niazi, MD}

Director, Department of Pathology, Albert Einstein College of Medicine, Bronx-Lebanon Hospital Center

\section{Alan Bloom, MD}

Clinical Associate Professor of Medicine, Albert Einstein College of Medicine, Bronx-Lebanon Hospital Center

\section{Bhavna Balar, MD}

Chief Department of Gastroenterology, Albert Einstein College of Medicine, Bronx-Lebanon Hospital Center

\section{Simeon Carvajal, MD}

Attending Physician, Albert Einstein College of Medicine, Bronx-Lebanon Hospital Center 